\title{
Orofaciodigital syndrome with mesomelic limb shortening
}

\author{
J BURN, C DEZATEUX, C M HALL, AND M BARAitSER
}

From The Queen Elizabeth Hospital for Sick Children, Hackney Road, and The Hospital for Sick Children, Great Ormond Street, London.

SUMmary Two sisters, the children of first cousin Pakistani Moslem parents, have unusual facies, tongue hamartomata, pre- and postaxial polydactyly, severe talipes, and mesomelic limb shortening associated with tibial dysplasia. Homozygosity for a recessive gene defect is probable. The phenotype resembles, but is distinct from, the orofaciodigital syndromes delineated to date. We suggest that this condition be labelled OFD IV.

Orofaciodigital (OFD) syndrome is characterised by a median pseudo-cleft of the lip, cleft palate, tongue lobulation and hamartomata, multiple oral frenulae, a flat face, hypoplastic zygomatic arch, and both preand postaxial polydactyly. Milia of the face, the absence of deafness, and bilateral preaxial polydactyly are features which help to distinguish type I from type II (Mohr), but the principal basis for this distinction is the differing patterns of inheritance. Type I behaves as an X linked dominant, lethal in the hemizygous male, while type II is autosomal recessive. ${ }^{1}$ In 1971 Sugarman et al ${ }^{2}$ reported a sib pair with 'jaw winking', supernumerary teeth, polydactyly, and mental retardation. This syndrome has been designated OFD III.

Abnormalities of the long bones are not a recognised feature of the OFD syndromes. Rimoin and Edgerton in $1967^{3}$ described two sibs with features of OFD II and abnormal proximal metaphyses of the tibiae and fibulae. A third sib, with similar digital features, was stillborn. Goldstein and Medina ${ }^{4}$ reported a sib pair with features of type II OFD syndrome, drawing attention to the dental anomalies. Both children were below the third centile for height, with mesomelic shortening in all four limbs. Radiographs revealed flared metaphyses in the long bones of the forearm and foreleg with abnormal constriction of the metaphyses of the proximal tibiae. Temtamy and McKusick, ${ }^{5}$ noting the earlier reports, described a child with the facial features of OFD, whose thorax was small and whose limbs were short, with, in particular, rounded proximal tibial metaphyses. They labelled this child and another with a hypoplastic epiglottis as examples of a Mohr-Majewski compound. The Majewski syndrome is a lethal recessive disorder in the short rib polydactyly category. Severe dysplasia of the tibiae and hypoplasia of the epiglottis are characteristic features.

Using the same eponym, Baraitser et $a l^{6}$ recently reported the older of the sibs described here, and suggested that this might represent a distinct recessive entity. We report a second affected child in the same sibship with the same features and review the classification of this syndrome.

\section{Case report}

III $\cdot 2$, who was the subject of an earlier report, ${ }^{6}$ was born on 9.9.81 to first cousin Pakistani Moslem

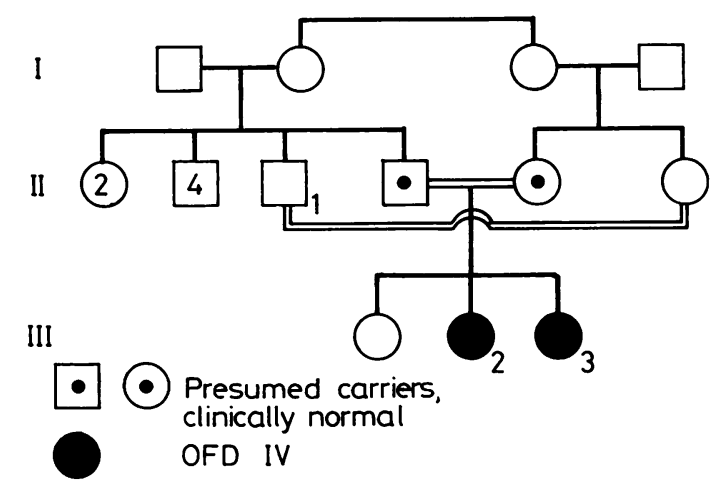

FIG 1 Family pedigree. 
TABLE Clinical features of the patients.

\begin{tabular}{|c|c|c|}
\hline & $I I I .2$ & III.3 \\
\hline Gestation & 33 weeks & 40 weeks \\
\hline Birth weight & $1520 \mathrm{~g}$ & $2870 \mathrm{~g}$ \\
\hline \multirow[t]{2}{*}{ Facial features } & Low set ears & Low set ears \\
\hline & Micrognathia & Micrognathia \\
\hline \multirow[t]{2}{*}{ Oral features } & Posterior cleft plate & High intact palate \\
\hline & Sublingual hamartomata & $\begin{array}{l}\text { Three sublingual hamartomata } \\
\text { Cleft of inferior alveolar ridge }\end{array}$ \\
\hline \multirow[t]{2}{*}{ Ocular features } & Mild proptosis & Mild proptosis \\
\hline & Oculomotor apraxia & Oculomotor apraxia \\
\hline \multirow[t]{3}{*}{ Skeletal features } & Hands: postaxial polysyndactyly & Hands: postaxial polysyndactyly \\
\hline & Feet: pre- and postaxial polysyndactyly & Feet: pre- and postaxial polysyndactyly \\
\hline & $\begin{array}{l}\text { Severe talipes equinovarus } \\
\text { Tibial dysplasia and generalised mesomelia }\end{array}$ & Severe talipes equinovarus \\
\hline \multirow{5}{*}{$\begin{array}{l}\text { Progress and } \\
\text { development }\end{array}$} & $\begin{array}{l}\text { Tibial dysplasia and generalised mesomelia } \\
\text { Recurrent chest infections }\end{array}$ & $\begin{array}{l}\text { Tibial dysplasia and generalised mesomelia } \\
\text { Recurrent chest infections }\end{array}$ \\
\hline & Failure to thrive & Gastro-oesophageal reflux requiring fundoplication \\
\hline & Delayed milestones & Failure to thrive \\
\hline & Bilateral congenital conductive hearing loss & Delayed milestones (?related to illness) \\
\hline & CT scan: mild cerebral atrophy & $\begin{array}{l}\text { Bilateral congenital conductive hearing loss } \\
\text { CT scan not yet done }\end{array}$ \\
\hline
\end{tabular}

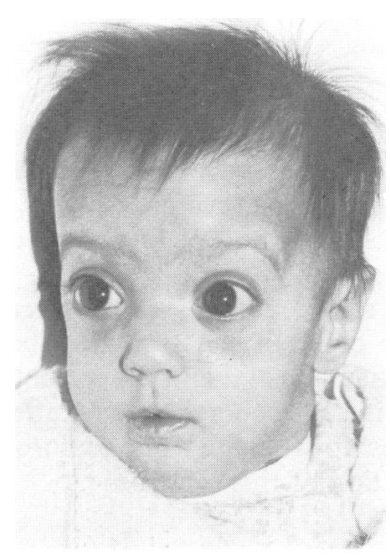

(a)

FIG 2 First affected child III.2.

(a) Facial appearance.

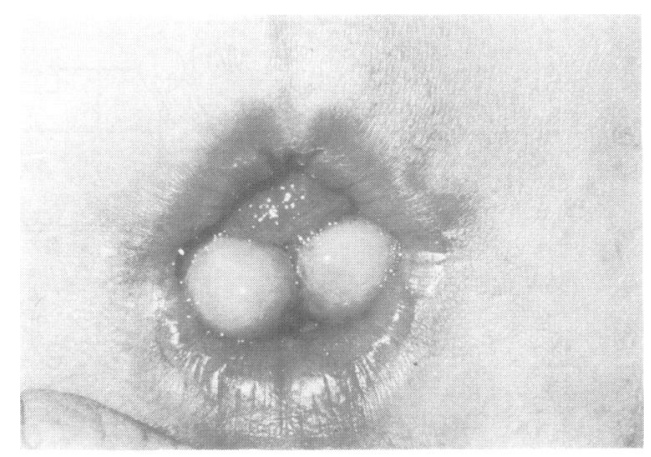

(b)

(b) Sublingual hamartomata. parents. By the time a diagnosis was reached in this $\subseteq$ child, the mother was pregnant again. The second $\overparen{\Phi}$ affected sib was born on 7.9.82. Fig 1 shows the $\vec{\varphi}$ pedigree and the table summarises the clinical features. Fig 2 shows the clinical and radiological features in III.2. Fig 3 shows the clinical and radiological features in the second affected sib III.3.
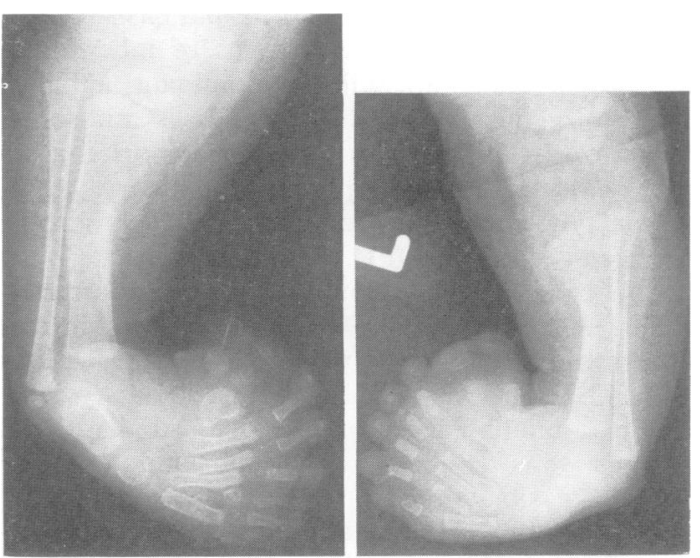

(c)

(c) AP $x$-ray of tibiae, fibulae, and feet. Symmetrical tibial shortening is present with mild lateral bowing of the mid shafts. The fibulae are long in relation to the tibiae and there are dislocations at knees and ankles. The right foot shows polysyndactyly (eight digits). The first metatarsal is short, broad, and rounded and the duplicated phalanges are correspondingly wide.

Postaxial polydactyly is also present. The left foot shows similar changes but there is also virtually no ossification of several middle and terminal phalanges. 

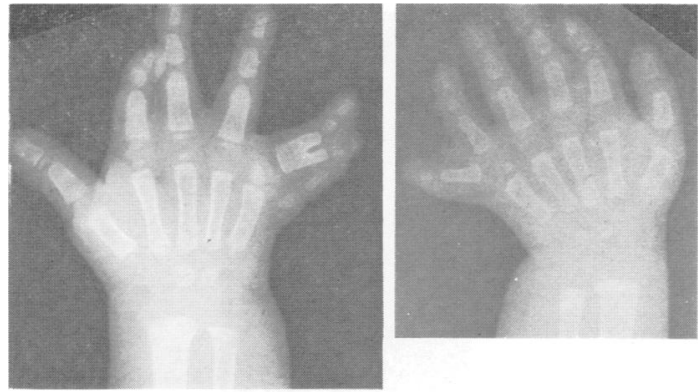

(d)

(d) PA x-ray of both hands. The right hand shows postaxial polydactyly (seven digits but only five metacarpals). Abnormal pseudoepiphyses are associated with the metacarpals. The index finger shows camptodactyly with shortening of the middle phalanx. The left hand also shows postaxial polydactyly (six digits but five metacarpals). The middle phalanges of the index and little fingers are abnormally short.
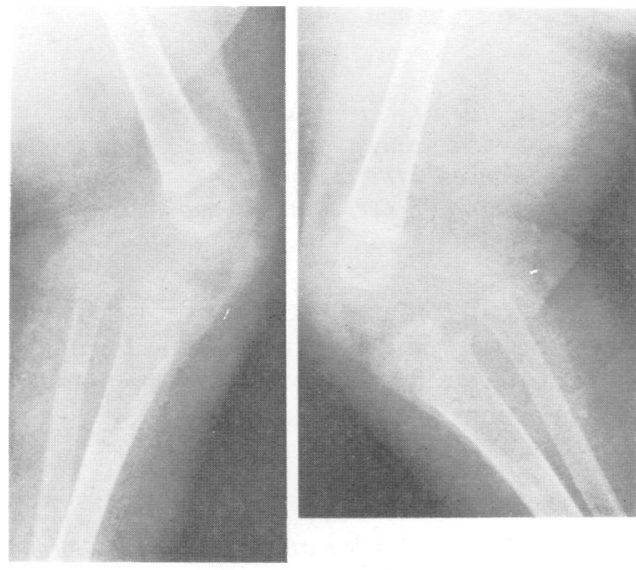

(e)

(e) Lateral $x$-ray of knees. Dislocation and proximal shortening of both tibiae.

Oculomotor apraxia is a defect of voluntary and optically induced horizontal eye movement with retention of voluntary vertical gaze. It may be associated with absence of the corpus callosum though this was not evident on the CT scan of III.2.

\section{Discussion}

The occurrence of the same pattern of malformation in female sibs is suggestive of autosomal recessive

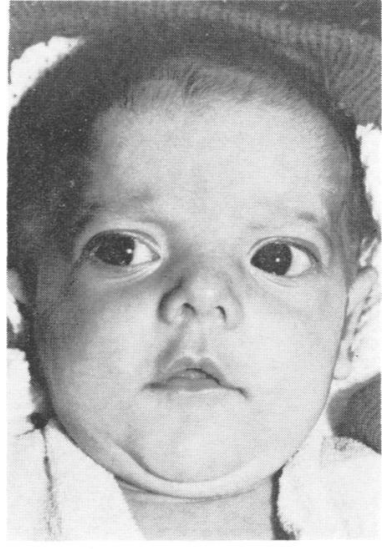

(a)

FIG 3 Second affected sib III.3.

(a) Facial appearance.

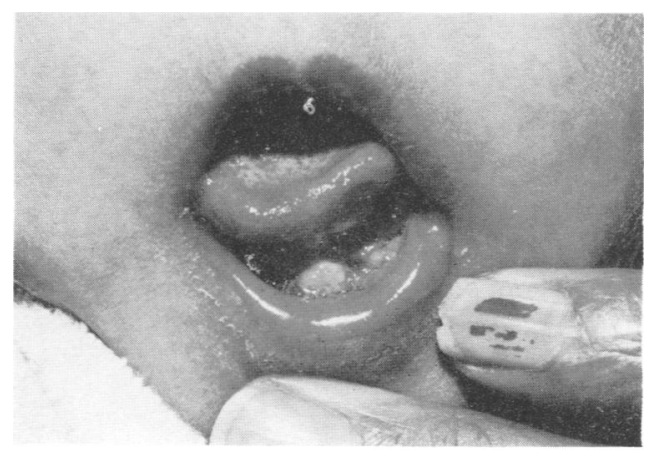

(b)

(b) Sublingual hamartomata.

inheritance. When the parents are healthy first cousins this genetic basis becomes very probable, even though the parents come from a group where inbreeding is frequent.

The mesomelic limb shortening, particularly involving the tibiae, is of importance in classification, antenatal diagnosis, and prognosis. The children in this report have many of the features of the OFD syndromes, but the specific defects of the long bones justify the separate designation of an OFD syndrome with mesomelia: OFD IV.*

*These children were presented (by $\mathrm{CMH}$ ) at the European Society of Paediatric Radiology, Paris 1983. The proposed designation OFD IV was accepted. 


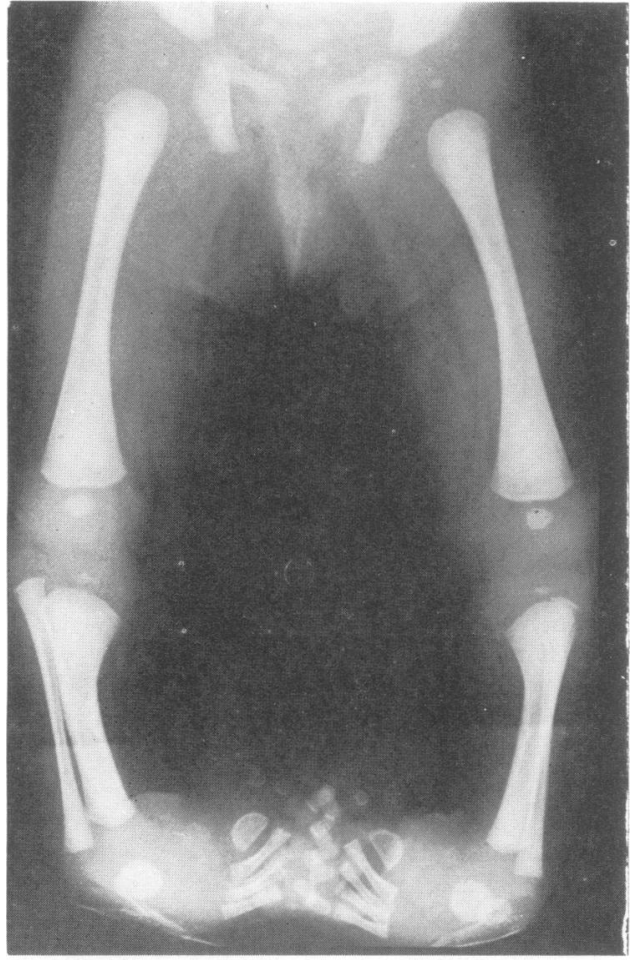

(c)

(c) AP $x$-ray of lower limbs. Symmetrical tibial shortening with dislocation at knees and ankles. There is preaxial polysyndactyly of the feet with duplication of the phalanges of the big toes and an abnormally rounded broad first metatarsal.

Following the birth of one affected child, antenatal diagnosis may be offered. An ultrasound scan to detect polysyndactyly and the abnormally short tibiae may be attempted and where doubt persists fetoscopy should be considered. This has been offered to the parents and also to their sibs who, as is seen in the pedigree, show comparable consanguinity and are therefore also at risk.

The abnormalities shown on the CT scan, together with the developmental delay noted clinically, support the view that significant mental retardation may be present in these sisters. It should be noted, however, that the sibs described by Goldstein and Medina $^{4}$ were of normal intelligence. The short dysplastic tibiae and the attendant joint instability constitute the other long term problem. Major orthopaedic intervention will be necessary to permit mobility.

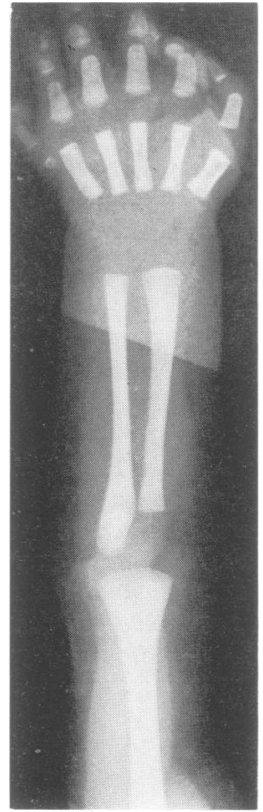

(d)

(d) PA x-ray of left forearm and hand. Postaxial polydactyly with a rudimentary sixth metacarpal associated with two phalanges. Mild camptodactyly is present and there is hypoplasia of several middle phalanges.

We are grateful to Dr M O Savage for permission to publish this case and to Mrs Melanie Barham and Ms Carol Reeves for preparation of the manuscript and illustrations respectively.

\section{References}

1 Smith DW. Recognizable patterns of human malformation. 3rd ed. Philadelphia: Saunders, 1982.

2 Sugarman GI, Katakia M, Menkes J. See-saw winking in a familial oral-facial-digital syndrome. Clin Genet 1971; 2:248-54

3 Rimoin DL, Edgerton MT. Genetic and clinical hetero- N geneity in the oral-facial-digital syndromes. $J$ Pediatr 1967;71:94-102.

4 Goldstein E, Medina JL. Mohr syndrome or oral-facialdigital II : report of two cases. J Am Dent Assoc 1974;89: $377-82$.

5 Temtamy S, McKusick VA. The genetics of hand malformations. Birth Defects 1978;XIV: No 3.

6 Baraitser M, Burn J, Fixsen J. A female infant wilh features of Mohr and Majewski syndromes: variable $T$ expression, a genetic compound, or a distinct entity? $J$ Med Genet 1983;20:65-7.

Correspondence and requests for reprints to $\operatorname{Dr} \mathrm{J} \stackrel{\mathbb{Q}}{\stackrel{\mathbb{Q}}{\mathscr{Q}}}$ Burn, Clinical Genetics Unit, Institute of Child Health, 30 Guilford Street, London WC1N 1EH. 